\title{
TEORIA CRÍTICA
}

\author{
INTRODUÇÃO
}

\author{
Ricardo Terra* \\ Luiz Repa**
}

Não é exagero dizer que a pesquisa sobre a tradição de pensamento conhecida pelo nome de "Teoria Crítica" passa por um momento de forte renovação no cenário acadêmico brasileiro e internacional. Entre os fatores principais que propiciaram essa renovação, do qual o presente dossiê pretende ser um exemplo, consta certamente o fato de ter ocorrido uma desmistificação do termo "Escola de Frankfurt". Tal termo, cuja origem tardia e utilização político-acadêmica foram analisadas por uma série de investigações históricas desde os meados dos anos setenta, acabou se tornando um obstáculo para a compreensão da complexidade e da fecundidade da Teoria Crítica. De maneira indevida, ele conferia uma homogeneidade doutrinária (a ideia de "escola") a autores tão distintos, ao mesmo tempo em que restringia seu alcance a uns poucos pensadores, fazendo perder de vista tanto o ambiente interdisciplinar diversificado como a conti-

* Doutor em Filosofia. Professor titular da Universidade de São Paulo.

Av. Luciano Gualberto 325. São Paulo-SP. ricardor@usp.br

** Doutor em Filosofia. Professor do Departamento de Filosofia da Universidade Federal do Paraná.luizrepa@uol.com.br nuidade dessa tradição nos tempos atuais.

Perdia-se de vista igualmente o que sustentava a verdadeira unidade dessa tradição no interior de sua evidente multiplicidade teórica e disciplinar: a constante busca de atualizar o diagnóstico de época segundo as exigências de apreender os potenciais emancipatórios inscritos na realidade das sociedades capitalistas contemporâneas e, simultaneamente, identificar os obstáculos ao desenvolvimento desses potenciais. Essas exigências foram postas por Horkheimer, em seu texto "Teoria Tradicional e Teoria Crítica", como os dois princípios que as distinguem. Como mostra o artigo de Rúrion Melo, apoiando-se nos estudos recentes de Marcos Nobre, esses princípios são articulados por Horkheimer ao se referir à obra de Marx como matriz da Teoria Crítica, e, ao mesmo tempo, orientar-se para um diagnóstico do capitalismo moderno bastante distinto do de Marx. O conceito de Teoria Crítica só surge, portanto, no momento em que componentes teóricos centrais do marxismo pareciam invalidados.

Dadas essas exigências da Teoria Crítica, entende-se a diversidade dos diagnósticos seja 
em relação aos potenciais e aos obstáculos para a emancipação, seja para a própria concepção de emancipação, sem que, com isso, a própria unidade dessa tradição se enfraqueça. Ao contrário, sua atualização constante, que frequentemente se realiza por meio de críticas severas entre os seus representantes, é a condição mesma da sua unidade e da sua continuidade. O presente dossiê ilustra esse ânimo próprio da Teoria Crítica de uma dupla forma: primeiro, por apresentar, em seu conjunto, aquela diversidade de diagnósticos; segundo, pelo fato de os colaboradores buscarem também renovar os potenciais teóricos dos autores analisados para os problemas da sociedade contemporânea.

Cabe mencionar ainda um terceiro aspecto em que as colaborações se deixam animar pelas exigências determinantes da Teoria Crítica. Seus autores participam diretamente ou são colaboradores frequentes do Núcleo Direito e Democracia do Centro Brasileiro de Análise e Planejamento (NDD/CEBRAP), o qual, há uma década, tem realizado pesquisas teóricas e empíricas sobre as tendências jurídicas, políticas e sociais contemporâneas, em um ambiente interdisciplinar que reúne pesquisadores de filosofia, direito, ciência política e sociologia. Tendo como referência inicial a obra de Habermas sobre direito e democracia, mas contando com uma grande heterogeneidade de perspectivas metodológicas e teóricas, o NDD se tornou um centro de formação, pesquisa e reflexão voltado para a teoria social em seu sentido amplo. Naturalmente, os diversos modelos de Teoria Crítica desenvolvidos desde a época de Horkheimer se tornaram objeto de investigação e discussão nesse núcleo. Com isso, acreditamos que o dossiê aqui apresentado permite, no interior de seus limites, oferecer uma contribuição importante e qualificada para a compreensão da Teoria Crítica, principalmente no que se refere à sua complexidade $\mathrm{e}$ fecundidade.

O artigo de Rúrion Melo, que abre o dossiê, toma por objeto os princípios da Teoria Crítica, propondo uma reconstrução de sua história a par- tir da questão sobre o significado da ideia de "emancipação". Também aqui, sobretudo aqui, apresenta-se o momento em que a conceitualização dessa forma de teoria por parte de Horkheimer passa por um distanciamento em relação a Marx. Pois em Marx e no marxismo em geral, a emancipação significou, na maioria das vezes, a configuração de uma sociedade do trabalho, que tomava como central a crítica ao "trabalho abstrato", próprio da lógica de reprodução do capital. Já Horkheimer e, com ele, Adorno principiam uma forte crítica ao potencial emancipatório da categoria de trabalho, cuja lógica é, então, aproximada à daquela da razão instrumental, conceito-chave com que ambos os pensadores buscam entender a realidade das sociedades capitalistas dos anos quarenta. Porém, segundo o autor, somente a partir de Habermas se conseguiu abrir novos sentidos para o conceito de emancipação, livrando-se do modelo produtivista. Com isso, também a oposição entre "reforma e revolução" deixa de ser, em princípio, um dilema para o pensamento de esquerda, uma vez que ambos os polos refletiam a mesma equação de identificar "emancipação" e "sociedade do trabalho".

Se o artigo de Rúrion Melo oferece uma ampla visão da Teoria Crítica a partir de uma questão nuclear como essa sobre os sentidos da emancipação, o texto de Luciano Gatti, que analisa os comentários de Walter Benjamin sobre Bertolt Brecht, apresenta, de maneira quase microscópica, como o interesse pela emancipação social se aloja na reflexão "estética" daquele pensador. Contrariando uma forte tendência da literatura de comentário, a de ver, em Benjamin, o filósofo da perda da experiência e, com isso, nostálgico das tradições pré-modernas, Luciano Gatti intenta descobrir, nas suas críticas literárias, no caso especialmente de um artista revolucionário como Brecht, as condições atuais da experiência urbana, explorando seus potenciais de negação da realidade capitalista.

Por sua vez, a contribuição de Luiz Repa foca um problema de natureza mais históricofilosófica e metodológica, tematizando o uso dos 
conceitos de negação determinada e de totalidade em Theodor W. Adorno, segundo sua proposta de fornecer um modelo eminentemente negativo de dialética. Reconstituindo a crítica de Adorno ao elo indissociável entre totalidade e negatividade na dialética hegeliana, o autor pretende mostrar, contudo, que também Adorno recorre a um conceito de totalidade social, com uma função explicativa e crítica. Esse recurso se daria em um nível macrológico, enquanto, em um nível micrológico, Adorno insiste na crítica à categoria de totalidade. A combinação desses níveis poderia ser entendida, segundo a hipótese interpretativa de Luiz Repa, a partir dos conceitos de crítica imanente e de ilusão socialmente necessária. Ao contrário de Hegel, Adorno pensa a negação determinada como uma crítica imanente voltada contra a falsa identidade e, portanto, a falsa totalidade em que se encontram os indivíduos socializados no capitalismo tardio.

A questão sobre o potencial emancipatório e seus bloqueios inscritos na realidade social reaparece nas contribuições de John Abromeit e de Felipe Gonçalves Silva, porém em contextos teóricos diversos. No artigo de John Abromeit, ela se apresenta como pano de fundo da análise específica sobre a crítica marcuseana da tecnologia. Contrapondo-se à leitura de que Marcuse é influenciado por Heidegger nessa crítica, o que suscita elogios ou reprovações, Abromeit parte da tese de que Marcuse assimila abordagens fenomenológicas sem comprometer o quadro teórico maior, dado pela compreensão marxiana da técnica como força produtiva. Dessa maneira, o autor procura analisar todas as principais etapas da crítica de Marcuse ao desenvolvimento tecnológico no capitalismo tardio, recuperando, para cada uma delas, o contexto histórico específico, a fim de mostrar que o filósofo nunca deixou de sublinhar o potencial emancipatório da técnica, mesmo nos momentos em que ela se converte em meio privilegiado de dominação social. Segundo Abromeit, a influência de Heidegger é bastante localizada, e tampouco deve servir de premissa para explicar o déficit democrático de Marcuse. Também nesse caso, tal déficit deve ser atribuído à dívida teórica para com Marx.

Já na contribuição de Felipe Gonçalves Silva, a questão sobre os potenciais emancipatórios e seus bloqueios se configura como fio condutor para uma reconstrução da teoria habermasiana do direito e da democracia. A partir do conceito habermasiano de emancipação, referido aos pressupostos de uma discussão isenta de dominação, Felipe Gonçalves Silva decifra as estratégias mais gerais do pensador para escapar tanto de um realismo cético como de um normativismo utópico a respeito daqueles potenciais. Ao mesmo tempo, o autor procura mostrar que a proposta de Habermas padece de algumas limitações importantes, tais como a restrição a um conceito de direito excessivamente vinculado à ideia de coerção, déficits sociológicos importantes acerca das patologias sociais contemporâneas e, por fim, a centralização igualmente excessiva do processo legislativo para a compreensão da política deliberativa. Contudo essas críticas devem ser, por fim, inseridas em uma correta compreensão da teoria habermasiana do discurso, ou seja, como um projeto inacabado a ser explorado conforme o fluxo das demandas dos movimentos sociais.

Por fim, o artigo de Nathalie Bressiani examina o modelo crítico de Nancy Fraser no contexto de sua discussão acirrada com Axel Honneth a respeito da melhor compreensão das demandas de justiça existentes nas sociedades modernas contemporâneas, ou seja, a discussão acerca da redistribuição ou reconhecimento como conceitos normativamente orientadores. O interesse da autora, no entanto, incide sobre os modelos de teoria social que estão na base da discussão entre Fraser e Honneth, os quais ela elucida, reconstruindo as críticas que eles dirigem a Habermas, especialmente à Teoria da ação comunicativa. Segundo Nathalie Bressiani, ainda que essas críticas apresentem muito semelhanças, sobretudo no que diz respeito à separação estanque entre as esferas da reprodução material e da reprodução simbólica, isto é, entre 
sistema e mundo da vida, elas se dirigem a resultados bastante distintos. Enquanto a teoria social de Honneth caminha para uma espécie de monismo normativo, centrado no conceito de reconhecimento, Fraser pretende atenuar o dualismo habermasiano, insistindo na interligação entre sistema e mundo da vida como fonte de injustiça, mas também na especificidade dessas esferas para a produção de diversas outras formas de subordinação social.

É preciso sublinhar, finalmente, que o presente dossiê não pretende, de modo algum, esgotar nem mesmo fornecer uma visão de conjunto a mais ampla possível da Teoria Crítica. Seria pos- sível abordar outros teóricos importantes dessa tradição, como Franz Neumann, Friedrich Pollock, Otto Kirchheimer, Iris Young, Seyla Benhabib, Klaus Günther, assim como variar os enfoques e os problemas tratados em cada um dos autores aqui analisados. Porém, como dissemos de início, o dossiê pretende refletir algo essencial para a ideia de Teoria Crítica: sua preocupação com o presente, com as potencialidades de uma sociedade emancipada e justa, com os obstáculos para a efetivação dessas potencialidades, sem querem criar, para isso, uma escola.

(Recebido para publicação em 30 de junho de 2011) (Aceito em 15 de julho de 2011)

Ricardo Terra - Doutor em Filosofia. Professor titular da Universidade de São Paulo. Coordenador o Núcleo Direito e Democracia do CEBRAP, desenvolvendo pesquisa sobre filosofia política e teoria crítica. Co-organizou "Direito e Democracia. Um guia de leitura de Habermas". São Paulo: Malheiros Editores, 2008; "Recht und Frieden in der Philosophie Kants". Berlin: Walterde Gruyter, 2008. Publicou Kant \& o direito. 1. ed. Rio de Janeiro: Zahar, 2004.

Luiz Repa - Doutor em Filosofia. Professor do Departamento de Filosofia da Universidade Federal do Paraná. Integra o Núcleo de Pesquisa Direito e Democracia do CEBRAP, desenvolvendo pesquisas na área de filosofia política e teoria crítica. Suas mais recentes publicações são: Hegel, Habermas e a modernidade. Dois Pontos: Curitiba, v. 7, p. 151-162, 2010; A transformação da filosofia em Jürgen Habermas: os papéis de reconstrução, interpretação e crítica. São Paulo: Esfera Pública, 2008; Reconhecimento da diferença na teoria crítica. In: Amarildo Luiz. (Org.). Cultura, diferença e educação. Porto Alegre: Sulina, 2010. 